\title{
Which Reimbursement System Fits Inpatient Palliative Care? A Qualitative Interview Study on Clinicians' and Financing Experts' Experiences and Views
}

\author{
Eva Schildmann, ${ }^{1}$ Farina Hodiamont, ${ }^{1}$ Reiner Leidl, ${ }^{2,3}$ \\ Bernd Oliver Maier, ${ }^{4}$ and Claudia Bausewein ${ }^{1}$
}

\begin{abstract}
Context: Internationally, a variety of reimbursement systems exists for palliative care (PC). In Germany, PC units (PCUs) may choose between per-diem rates and diagnosis-related groups (DRGs). Both systems are controversially discussed.

Objectives: To explore the experiences and views of German PCU clinicians and experts for PCU financing regarding per-diem rates and DRGs as reimbursement systems with a focus on (1) cost coverage, (2) strengths and weaknesses of both financing systems, and (3) options for further development of funding PCUs.

Design: Qualitative semistructured interviews with PCU clinicians and experts for PCU financing, analyzed by thematic analysis using the Framework approach.

Setting/Subjects/Measurements: Ten clinicians and 13 experts for financing were interviewed June-October 2015 on both reimbursement systems for PCU.

Results: Interviewees had divergent experiences with both reimbursement systems regarding cost coverage. A described strength of per-diem rates was the perceived possibility of individual care without direct financial pressure. The nationwide variation of per-diem rates and the lack of quality standards were named as weaknesses. DRGs were criticized for incentives perceived as perverse and inadequate representation of PC-specific procedures. However, the quality standards for PCUs required within the German DRG system were described as important strength. Suggestions for improvement of the funding system pointed toward a combination of perdiem rates with a grading according to disease severity/complexity of care.

Conclusions: Expert opinions suggest that neither current DRGs nor per-diem rates are ideal for funding of PCUs. Suggested improvements regarding adequate funding of PCUs resemble and supplement international developments.
\end{abstract}

Keywords: diagnosis-related groups (DRGs); economics; financing; funding; palliative care; per-diem rates; qualitative research; reimbursement

\section{Introduction}

G IVEN DEMOGRAPHIC CHANGE and increasing prevalence of chronic illness and multimorbidity, the need for palliative care (PC) is expected to rise substantially over the next decades. ${ }^{1,2}$ To meet this growing demand, effective funding mechanisms for PC are paramount. ${ }^{3-5}$ At present a wide variation of funding models for $\mathrm{PC}$ in various countries have been described. ${ }^{4}$ For making decisions about adequate funding models, it is important to understand the models of PC provision and the costs of PC. However, while there is evidence that $\mathrm{PC}$ is cost saving compared with usual care, the

\footnotetext{
${ }^{1}$ Department of Palliative Medicine, University Hospital, Ludwig-Maximilians-Universitaet (LMU) Munich, Munich, Germany.

${ }^{2}$ Institute of Health Economics and Health Care Management, Helmholtz Zentrum Munich-German Research Center for Environmental Health, Munich, Germany.

${ }^{3}$ Munich School of Management, Institute of Health Economics and Health Care Management, Munich Center of Health Sciences, Ludwig-Maximilians-Universitaet (LMU) Munich, Munich, Germany.

${ }^{4}$ Department for Palliative Medicine and Interdisciplinary Oncology, St. Josef-Hospital, Wiesbaden, Germany.

Accepted April 25, 2019.
} 
evidence regarding the costs of PC provision is still sparse, and little is known about the cost coverage and the efficiency impacts achieved by different reimbursement systems. ${ }^{3,5-13}$ The reimbursement of PC is controversially discussed worldwide. ${ }^{4,14}$ A central aspect in the debate is the argument that $\mathrm{PC}$ focuses on individual patient and family needs regardless of the underlying diagnosis. Therefore, reimbursement by means of diagnosis-related groups (DRGs), a case-based system mainly classified by main diagnosis or procedure, has been criticized. ${ }^{15-17}$ In Australia, where the German DRG system is derived from, ${ }^{18}$ it is acknowledged that $\mathrm{PC}$ is not adequately classified by DRGs and requires a different classification approach. ${ }^{19-23}$

In Germany, PC units (PCUs) in hospital, different from the situation in most other countries, can choose between two reimbursement systems: per-diem rates, which are locally negotiated between the hospitals and the insurance companies, and DRGs. ${ }^{24}$ In the German DRG system, a procedure code for specialist PC (SPC) was introduced, defined by criteria for acknowledgement of SPC and the duration of care provision. A supplementary fee is provided in addition to the standard DRG reimbursement for SPC greater than or equal to seven days, increasing with the duration of SPC. ${ }^{17}$
To our knowledge, so far, no study has explored stakeholders' views and experiences regarding different reimbursement systems for PC in depth. A sample of German stakeholders is particularly interesting in this respect, as they have experience of one or two reimbursement systems within one country where different reimbursement systems exist. Alongside health economic analyses of the costs and reimbursement situation in PC, these data can be beneficial for the future refinement of funding systems. ${ }^{4}$

The aim of this study was therefore to explore the experiences and views of PC clinicians and experts for financing of PCUs in Germany regarding per-diem rates and DRGs as reimbursement systems with a focus on (1) cost coverage, (2) perceived strengths and weaknesses of both financing systems, and (3) options for further development of reimbursement systems for PCUs.

\section{Methods \\ Design}

Qualitative interview study with semistructured expert interviews, complying with COREQ criteria. ${ }^{25}$ This was part of a larger study on complexity and financing in inpatient and

Table 1. Characteristics of the Interviewed Experts with Expertise in PCU Financing $(N=23)$

\begin{tabular}{|c|c|c|c|}
\hline & $\begin{array}{l}\text { Total group } \\
\quad \mathrm{n}=23\end{array}$ & $\begin{array}{l}\text { Clinical experts } \\
\mathrm{n}=10\end{array}$ & $\begin{array}{l}\text { Financing experts } \\
\qquad \mathrm{n}=13\end{array}$ \\
\hline Professional background & & $\begin{array}{c}\text { Physicians } n=7 \\
\text { Nurses } n=3\end{array}$ & $\begin{array}{l}\text { Representatives of: } \\
\text { Hospital financial controlling depts.: } n=3 \\
\text { German hospital association: } n=1 \\
\text { Health insurance companies: } n=3 \\
\text { German palliative care and hospice associations: } n=3 \\
\text { Health care system researchers: } n=2 \\
\text { Institute for the Hospital Remuneration System } n=1\end{array}$ \\
\hline \multicolumn{4}{|r|}{ Institute for the Hospital Kemuneration System $n=1$} \\
\hline $\begin{array}{l}\text { Male } \\
\text { Female }\end{array}$ & $\begin{array}{l}13 \\
10\end{array}$ & $\begin{array}{l}4 \\
6\end{array}$ & $\begin{array}{l}9 \\
4\end{array}$ \\
\hline $\begin{array}{l}\text { Years of PC experience } \\
\text { (median, range) }\end{array}$ & $11(2-30)$ & $17(5-30)$ & $10(2-27)$ \\
\hline \multicolumn{4}{|l|}{ University affiliation } \\
\hline Yes & 4 & 3 & 1 \\
\hline No & 9 & 7 & 2 \\
\hline Not applicable & 10 & 0 & 10 \\
\hline \multicolumn{4}{|l|}{ Area } \\
\hline Urban & 10 & 8 & 2 \\
\hline Rural & 3 & 2 & 1 \\
\hline Not applicable & 10 & 0 & 10 \\
\hline \multicolumn{4}{|l|}{ Geographical region } \\
\hline North & 1 & 1 & \\
\hline East & 2 & 2 & 3 \\
\hline South & 7 & 4 & \\
\hline West & 3 & 3 & 10 \\
\hline National & 10 & 0 & \\
\hline \multicolumn{4}{|l|}{ Experience with } \\
\hline Per-diem rates only & 3 & 3 & 0 \\
\hline German DRGs only & 7 & 5 & 2 \\
\hline Both reimbursement systems & 13 & 2 & 11 \\
\hline
\end{tabular}

University affiliation and area is only given for those financing experts who work in a hospital financial controlling departments, for all others it is depicted as "not applicable."

DRG, diagnosis-related group; PC, palliative care; PCU, PC unit. 
outpatient PC. For more methodological details, see Supplementary Table S1 (COREQ criteria), Supplementary Table S2 (interview guide) and a related publication of this study. ${ }^{26}$

\section{Setting and participants}

To prevent bias and include various perspectives, the sample included clinical experts (physicians and nurses) and experts with expertise in PC financing (representatives of hospital financial controlling departments, health insurances, German PC and hospice associations, health care research), based on suggestions from the research team, collaborating partners and German PC associations.

Inclusion criteria for clinical experts were (1) a minimum of five years working experience in PC and (2) a management/ supervising/leadership role. Inclusion criteria for financing experts were (1) PC as an area of responsibility in the expert's professional daily routine and (2) a minimum of two years working experience in the respective area of responsibility. Purposive sampling was used to ascertain variations of the sample regarding the following criteria: profession, university affiliation, rural or urban area, geographical region.

The study was approved by the research ethics committee at the Medical Faculty of Ludwig-Maximilians-Universitaet Munich (01/2015; reference number 24-15). Respondents provided written informed consent.

\section{Data collection and analysis}

Two separate interview guides were developed and piloted for clinical and financing experts. The development of the interview guides followed the four-step procedure according to Helfferich: collecting, reviewing, sorting, subsuming. ${ }^{27}$

All interviews were audiorecorded and transcribed verbatim. The data were reviewed parallel to the interviews to be able to adjust the interviews' number to achieve data saturation. Data were analyzed by thematic analysis, applying the Framework approach, using NVivo. ${ }^{28}$ The main categories were identified in advance in accordance with the research aim, and the subcategories were developed inductively in close collaboration of ES, FH, and CB. Coding consistency was ensured by applying a coding guide and the verification of intra-coder reliability for eight, and inter-coder reliability for four interview transcripts. Generation of themes was consented within the research team. Due to the nature of the data and in line with our aim, we provide a descriptive account without additional development of concepts.

\section{Results}

Overall, 42 interviews on complexity and financing in PC were conducted between June and October 2015-with experts with inpatient and outpatient PC experience. Forty three out of forty eight invited experts (90\%) accepted the invitation. Reasons for decline were lack of time $(n=4)$ and too little experience in PC $(n=1)$. One interview was cancelled on short notice because of a clinical emergency. Twenty three interviewees had experience with PCU financing (10 clinical, 13 financing experts), and the analysis of these 23 interviews is reported in this study. Twenty experts had experience with DRGs, $n=16$ with per-diem rates. Median interview duration was 55 minutes (range: 19-113 minutes). Characteristics of the interviewees are summarized in Table 1.
We present the stakeholders' experiences and views regarding per-diem rates and DRGs as reimbursement systems for PCUs with a focus on (1) cost coverage, (2) perceived strengths and weaknesses, and (3) options for further development of reimbursement systems for PCUs.

All themes were named by clinical and financing experts. For participants' quotations, see Table 2.

\section{Cost coverage}

Experts reported divergent experiences regarding the cost coverage for PCUs by per-diem rates and DRGs. The spectrum included the experience that both systems are cost covering, that cost coverage is only provided by one of the systems, and the view that both are not cost covering (quotations 1 and 2, Table 2).

Regarding per-diem rates, the experts named the nationwide variability of the rates as probable reason for differing experiences regarding cost coverage, as they are locally negotiated between the hospitals and the insurance companies. In terms of the DRG system, possible reasons for the different experiences regarding cost coverage are, according to the experts, (1) differences regarding local infrastructure costs which are not reflected in the DRG system, (2) differences in the clinical characteristics of patients cared for by the PCUs, and (3) differences in accounting for external funding for some care aspects when considering cost coverage (quotation 3 ).

\section{Strengths and weaknesses of per-diem rates and DRGs}

Main strengths and weaknesses of both systems from the experts' perspective are summarized in the following and in Table 3.

Strengths of per-diem rates-weaknesses of the DRG system. The perceived possibility of individual needs- and demand-oriented care without direct financial pressure was described as a strength of per-diem rates by the experts (quotation 4, Table 3). Accordingly, the perceived economic pressure with sanctions and perverse incentives to tailor treatment primarily toward financing were criticized as weakness of the DRG system or its application. Examples given for such incentives perceived as perverse were early discharge to "generate more cases" (CE-21) as well as treatment for at least seven days to fulfill the requirements for the supplementary fee for SPC (quotation 5).

Experts argued that, under the premise of an appropriate per-diem rate, a SPC-specific spectrum of care and, therefore, a higher quality of care was possible. From the experts' perspective, the multiprofessionalism and complexity of SPC-specific procedures are not adequately represented in the DRG system (quotation 6). Other examples of care not adequately represented in the DRG system were the focus on communication instead of technical procedures, "respite" admissions to give the informal carers a break or a prolonged length of stay while waiting for a hospice bed.

Another mentioned weakness of the DRG system was the burden for the SPC team caused by the lack of adequate honoring of the SPC-specific work, the economic pressure, the time expenditure for documentation, and the perceived pressure to justify the own practice toward the insurance companies. 
Table 2. Participants' Quotations Illustrating the Presented Results

\begin{abstract}
Cost coverage
Quotation 1 "Well, there are people who say, no matter whether we have per-diem rates or DRGs, the money is sufficient." (FE-10)

Quotation 2 "Well, we know our cost and reimbursement situation and know, which results we make with our PCU, and so far it is not cost-covering (authors' comment: in the DRG system), but was not cost-covering with per-diem rates, either." (FE-4)

Quotation 3 "Well, I know that in 2014 we were cost-covering (authors' comment: using the G-DRG system) for what the hospital calculates for us. However, in that it is it not taken into account that very much of that, let me say, all that differentiates us from a normal internal medicine ward is not financed via this system, but via third-party funds or charities." (CE-1)

Strengths of per-diem rates-weaknesses of the DRG system

Quotation 4 "One would wish that our care is needs-oriented and relationship-oriented, that, as it were, also the financing is adapted to this needs-orientation. And this, of course, is a lot easier to be done in a system where I have per-diem rates." (CE-21)

Quotation 5 "Then (authors' comment: in the per-diem rates system) one is not so much under this pressure. As it is (authors' comment: in the DRG system), one is always, one can say by the system, that forces one to cheat, that one says, we now keep this patient for seven days, to pick up the supplementary fee, right? (authors' comment: supplementary fee for SPC, only paid for a minimum duration of SPC of seven days.) Well, this is a way of thinking that I, where I try not to give in to that, right? (CE-17)

Quotation 6 "And be able to offer a very, very differentiated concept of care (authors' comment: in the per-diem rates system). Including really wonderful co-therapies, like music therapy, regular physiotherapy. And implement really great concepts, including care for informal carers that is very, very important. That in my opinion misses out in the DRG calculation."(FE-15)

Quotation 7 "The big, big advantage of per-diem rates in the DRG system is that every transfer to the PCU with perdiem rates is a discharge from the DRG system. And the transferring department can keep its whole DRG (authors' comment: what was meant was 'the whole DRG reimbursement sum'). There is competing and fighting (authors' comment: what was meant was 'competing between the involved departments of the hospitals') where it is not like that." (CE-23)

Strengths of the DRG system-weaknesses of per-diem rates

Quotation 8 "By the Operation and Procedure Code (authors' comment: defines requirements as precondition for receiving the supplementary fee for SPC) at least certain structure characteristics and quality criteria are defined. And that we do not know for per-diem rates, except that the PCU has to be a separate unit with more than five beds, but there are no preconditions regarding staff structure, team meetings and so on." (CE-21)

Quotation 9 "Via the DRG financing you have a uniform financing all over Germany, simply. On the part of the cost units that has more justice of reimbursement, because you reimburse the SPC in Munich in the same way as the SPC in Cologne. That was not the case with per-diem rates."(FE-1)

Suggestions for the future development of financing PCUs

Quotation 10 “Many PCUs try such an 'early integration'. That means, we also have people here with chemotherapies, (...) for which we get the supplementary fee in the DRG system (authors' comment: In the G-DRG system, supplementary fees are provided for certain procedures such as chemotherapies). We need that then in the per-diem rates system, too. If we want to treat these people, if we want to do diagnostic tests or we have to for symptom control and for the early integration, I am not yet sure how this works in the per-diem rates system." (CE-19)

Quotation 11 “'(...) there are no specific DRGs for PC. There is only the supplementary fee (authors' comment: supplementary fee for SPC in the German DRG system). There must be some factors or codes which reflect the care provided in PC."'(FE-4)

Quotation 12 "Maybe it would also be an interesting alternative to simply compare it and reimburse via per-diem rates, but also to take into account the disease severity and the care that you provide."(FE-1)
\end{abstract}

CE, clinical expert; FE, financing expert; SPC, specialist PC.

The clear attribution of reimbursement to the respective hospital departments involved in the patient's care was named as another strength of the per-diem rates. In the DRG system, where the reimbursement is either split between the treating departments or attributed in total to the discharging department, usually the PCU, the competition for reimbursement between the departments was criticized (quotation 7). According to the experts, this impedes transfers of patients to the PCU.

Strengths of the DRG system-weaknesses of per-diem rates. Experts saw the link of the reimbursement to quality criteria as an important strength of the DRG system:
Fulfilling the given requirements for structures and processes of PCUs is the precondition for receiving the supplementary fee for SPC. The lack of such quality standards in the current per-diem rates system was judged by the experts as one of the system's most important weaknesses (quotation 8).

Another strength of the DRG system mentioned by the experts is the nationwide uniformity of the system, ensuring justice in allocating funds. In the per-diem rates system, experts criticized the diversity of per-diem rates, and thus the variation of funding of PCUs across the country (quotation 9).

The transparency created by collection of all DRG data by a central institute was seen as an additional strength of the 
Table 3. Summary of Strengths and Weaknesses of Per-Diem Rates and DRGs as Reimbursement Systems for Palliative Care Units from the Experts' Perspective

\begin{tabular}{|c|c|c|}
\hline Category & Per-diem rates & $D R G s$ \\
\hline Individual, needs- and demand-oriented care supported & Yes & No \\
\hline $\begin{array}{l}\text { Economic pressure with sanctions and incentives perceived } \\
\text { as perverse }\end{array}$ & Little & Yes \\
\hline $\begin{array}{l}\text { SPC-specific spectrum of care, multiprofessionalism and } \\
\text { complexity of care represented } \rightarrow \text { high quality of care } \\
\text { supported }\end{array}$ & Yes & No \\
\hline Time expenditure for documentation & Little & Yes \\
\hline $\begin{array}{l}\text { Perceived pressure to justify the own practice toward the } \\
\text { insurance companies }\end{array}$ & $\begin{array}{l}\text { Questionable if less } \\
\text { than in DRG system }\end{array}$ & Yes \\
\hline $\begin{array}{l}\text { Burden for the SPC team by the aforementioned weaknesses } \\
\text { of the system }\end{array}$ & Not mentioned & Yes \\
\hline $\begin{array}{l}\text { Clear attribution of reimbursement to the respective hospital } \\
\text { departments involved in the patient's care }\end{array}$ & Yes & No \\
\hline $\begin{array}{l}\text { Competition for reimbursement between the departments, } \\
\text { impeding transfers of patients to the PCU }\end{array}$ & No & Yes \\
\hline Link of the reimbursement to quality criteria & No & Yes \\
\hline $\begin{array}{l}\text { Uniformity of the system, ensuring justice in allocating } \\
\text { funds }\end{array}$ & No & Yes \\
\hline Transparency & No & Yes \\
\hline $\begin{array}{l}\text { Potential perverse incentive for unnecessary prolongation of } \\
\text { the length of stay }\end{array}$ & Yes & $\begin{array}{l}\text { See above and text for } \\
\text { perverse incentives }\end{array}$ \\
\hline
\end{tabular}

Strengths in bold.

DRG system, whereas the per-diem system was perceived as a "black box" (FE-10).

An unnecessary prolongation of the length of stay was mentioned as potential perverse incentive of the per-diem rates system.

\section{Suggestions for the future development of financing PCUs}

Regarding the future development of financing PCUs, the experts emphasized the need of linking the reimbursement to structure and process quality standards such as qualifications of the team members or weekly multidisciplinary case discussions-especially in the per-diem rate system, where such standards are currently lacking. The adequate reimbursement of patients treated on the PCU early in the disease trajectory ("early integration") and potentially receiving chemotherapy or diagnostic tests was seen as an important challenge for the future development of the reimbursement systems. This applies especially to the current per-diem rate system (quotation 10).

For further development of the DRG system, the generation of (1) more specific codes for SPC (quotation 11) or of (2) an own cost center for PC in the national calculation system was suggested.

Experts made concrete suggestions for further development of the current reimbursement systems such as a blended system of per-diem rates combined with a grading according to disease severity and complexity of care, similar to the current system for psychiatry in Germany. ${ }^{29}$

\section{Discussion}

To our knowledge, this is the first study exploring experts' experiences and views on specific reimbursement systems for PCUs, in this case DRGs and per-diem rates, in a country where both systems are used concurrently. Important findings are first that both systems can be cost-covering or not cost-

covering, depending on the specific local circumstances. Second, in the experts' opinion, neither DRGs nor per-diem rates are ideal for funding PCUs, as both have important weaknesses. Third, the experts' suggestions for improvement of the funding system included a combination of per-diem rates with a grading according to disease severity and complexity of care, comparable to international developments.

\section{Cost coverage}

The experts' experiences for the two reimbursement systems varied from being cost covering to not being cost covering. This is self-explanatory in the case of the per-diem rates, which are locally negotiated and therefore vary across the country. ${ }^{30}$

For the DRG system, which offers identical reimbursement nationwide and for which a recent study demonstrated that it did not adequately reproduce costs for PCUs, the reasons mentioned by the experts for the variability of cost coverage are more diverse. ${ }^{9}$ They include special local circumstances such as infrastructure costs and specific patient characteristics as well as variations in internal allocation of DRG reimbursement to the individual hospital departments. Some hospitals split the DRG reimbursement between departments, others allocate the money to the discharging department. As the PCU usually is the discharging department, it receives more money in the latter case and is therefore more likely to break even.

This highlights that, according to the experts, not the systems themselves, but rather the specific conditions where they are used determine cost coverage. Consequently, these local conditions have to be considered to realistically judge the financing situation of PCUs.

\section{Strengths and weaknesses of the reimbursement systems}

Interestingly, all presented themes were named by at least one financing and one clinical expert which led to a comprehensive 
overlap of themes between the two groups. This may be related to the study focusing on specific issues in a field of practical relevance, combined with experience in financing by per-diem and DRGs in both expert groups (Table 1).

From the experts' point of view, both systems have important weaknesses in their current form. In both systems, potential perverse incentives were criticized, jeopardizing quality of care: in the per-diem rate system the unnecessary prolongation of length of stay, in the DRG system either early or delayed discharge, and orientation of treatment planning toward fulfilling the system's requirements. At least parts of the results are not restricted to PC, as highlighted by a recent qualitative interview study regarding experiences of the German DRG system in general: These experts also criticized the economic pressure, perverse incentives to orient treatment toward financing irrespective of needs, and the consecutive burden for the care team. ${ }^{31}$

The described strengths demonstrate features also identified internationally as important for funding models for PC, namely nationwide uniformity and transparency of the system, providing stable and predictable funding. ${ }^{4,14}$ The latter is one of six "desirable features" of PC funding models identified by Groeneveld et al., to promote quality and equity of care. ${ }^{4}$ The strengths of the reimbursement systems named by the experts supplement these desirable features of PC funding models by emphasizing the importance of supporting needs-based care and a SPC-specific spectrum of care as well as the link of the reimbursement system to quality standards. ${ }^{4}$

\section{Suggestions for the future development of financing PCUs}

For the future development of the reimbursement system, the experts made general and concrete suggestions. First, they emphasized the need for linking the reimbursement system to national quality standards. This corresponds to, for example, quality hurdle payment models discussed internationally. ${ }^{32}$ The structure and process standards proposed by the experts are in line with the criteria required in the current German DRG-system and with the ones posed by public authorities in other countries. ${ }^{4,17}$ Second, experts demanded that the future reimbursement system supports early access to PC by ensuring adequate reimbursement for the care of patients who are treated on the PCU early in their course of disease. Early access to PC is an internationally acknowledged policy goal, and supporting it is also one of the six desirable features of PC funding systems identified by Groeneveld et al. ${ }^{4,33}$

A concrete suggestion for the future development of reimbursement was a blended system of per-diem rates combined with a grading system according to disease severity and complexity of care, similar to approaches in other countries: In the United States, the traditional DRG-system has been modified by taking into account disease severity, better reflecting resource use in PC. ${ }^{34,35}$ Australia has implemented a blended PC reimbursement system outside the DRG system, based on a casemix classification according to phase of illness, functional status, severity of symptoms and age, combined with per-diem rates, and specific service use variables. $^{4,21,23,36}$ In the U.K., a similar payment model is currently under development. ${ }^{37,38}$

Such blended models ideally reflect the resource use for the patients' care better than "single-component" reimbursement systems, and provide less perverse incentives. However, it should be noted that multicomponent reimbursement systems may also incur countervailing incentives, as shown for performance-related payment systems. ${ }^{39}$ Overall, experts' suggestions for improvements of the funding system resemble and supplement current international developments. Theoretical and empirical analyses of blended reimbursement systems are needed.

\section{Strengths and limitations of this study}

A strength of this qualitative approach is that the experts could express their experiences and views of the reimbursement systems in depth. We used a well-defined, rigorous approach to analysis with consensus finding within the research team for generation of codes and themes.

A limitation of this study is the relatively small sample size. However, with the sampling procedure described, experts covering a predefined range of different aspects of experience were included and saturation was achieved. The reported experiences and views reflect the experience in one country, Germany, only, which is a potential limitation. The strength of this approach is that all experiences refer to the two systems as they are currently used in Germany, that is, a comparable situation. It is a particular strength of the study that some of the experts were able to compare the two systems based on own experiences with both.

\section{Conclusion}

Clinical as well as financial expert opinions suggest that neither the current DRGs nor per-diem rates are ideal for funding of PCUs. Suggested improvements regarding adequate funding of PCUs resemble and supplement international developments. In addition to health economic evaluations, ideally including patient-reported outcomes and other quality metrics, experiences and views of clinical and financing experts should be further explored and considered when further developing funding models for $\mathrm{PC}$ - to ensure high-quality, effective care, equity of care provision and early access to care.

\section{Acknowledgment}

The authors would like to thank all the experts who shared their experiences and views regarding financing of PCUs in the expert interviews.

\section{Author Disclosure Statement}

No competing financial interests exist.

This work was supported by a private charity. This charity does not wish to have its name published, but it has been revealed to the editors. This organization had no role in the design of the study, the collection, analysis and interpretation of data, and the writing of the article.

\section{Supplementary Material}

Supplementary Table S1 Supplementary Table S2 


\section{References}

1. Etkind SN, Bone AE, Gomes B, et al.: How many people will need palliative care in 2040? Past trends, future projections and implications for services. BMC Med 2017;15:102.

2. Simon ST, Gomes B, Koeskeroglu P, et al.: Population, mortality and place of death in Germany (1950-2050) Implications for end-of-life care in the future. Public Health 2012;126:937-946.

3. Gardiner C, Ingleton C, Ryan T, et al.: What cost components are relevant for economic evaluations of palliative care, and what approaches are used to measure these costs? A systematic review. Palliat Med 2017;31:323-337.

4. Groeneveld EI, Cassel JB, Bausewein C, et al.: Funding models in palliative care: Lessons from international experience. Palliat Med 2017;31:296-305.

5. Murtagh FEM, Groeneveld EI, Kaloki YE, et al.: Capturing activity, costs, and outcomes: The challenges to be overcome for successful economic evaluation in palliative care. Prog Palliat Care 2013;21:232-235.

6. McCaffrey N, Cassel JB, Coast J: An economic view on the current state of the economics of palliative and end-of-life care. Palliat Med 2017;31:291-292.

7. Smith S, Brick A, O'Hara S, et al.: Evidence on the cost and cost-effectiveness of palliative care: A literature review. Palliat Med 2014;28:130-150.

8. May P, Garrido MM, Del Fabbro E, et al.: Does modality matter? Palliative care unit associated with more costavoidance than consultations. J Pain Symptom Manage 2017; 55:766-774.e4.

9. Vogl M, Schildmann E, Leidl R, et al.: Redefining diagnosis-related groups (DRGs) for palliative care - a cross-sectional study in two German centres. BMC Palliat Care 2018;17:58.

10. Pinderhughes ST, Lehn JM, Kamal AH, et al.: Expanding palliative medicine across care settings: One health system experience. J Palliat Med 2018;21:1272-1277.

11. Fitzpatrick J, Mavissakalian M, Luciani T, et al.: Economic impact of early inpatient palliative care intervention in a community hospital setting. J Palliat Med 2018;21:933-939.

12. May P, Normand C, Cassel JB, et al.: Economics of palliative care for hospitalized adults with serious illness: A meta-analysis. JAMA Intern Med 2018;178:820-829.

13. May P, Cassel JB: Economic outcomes in palliative and end-of-life care: Current state of affairs. Ann Palliat Med 2018;7:S244-S248.

14. Duckett S: Aligning policy objectives and payment design in palliative care. BMC Palliat Care 2018;17:42.

15. Roeder N, Klaschik E, Cremer M, et al.: DRGs in der Palliativmedizin: Ist die palliativmedizinische Begleitung Schwerstkranker pauschalierbar? [DRGs in palliative care: Can palliative care for the severly ill be grouped into lump sums?]. das Krankenhaus 2002;12:1000-1004.

16. Weber M: Fallpauschalen: Sterbenden Patienten nicht angemessen [Case-based lump sums: Not adequate for dying patients]. Dtsch Aerztebl 2013;110:A-2272/C-1934.

17. Stevens S, Kloke M: Palliativkomplexbehandlung in der Onkologie. Mehr als ein Abrechnungsmodell? (Palliative oncology patients needing complex treatment. More than a billing example?). Onkologe 2013;84:408-414.

18. Vogl M: Assessing DRG cost accounting with respect to resource allocation and tariff calculation: The case of Germany. Health Econ Rev 2012;2:15.
19. Eagar K, Cromwell D, Kennedy C, et al.: Classifying subacute and non-acute patients: Results of the New South Wales Casemix Area Network study. Aust Health Rev 1997;20:26-42.

20. Eagar K, Innes K: Creating a Common Language: The Production and Use of Patient Data in Australia. Canberra: Department of Health, Housing and Community Services, 1992.

21. Gordon R, Eagar K, Currow D, et al.: Current funding and financing issues in the Australian hospice and palliative care sector. J Pain Symptom Manage 2009;38:68-74.

22. Eagar K, Gordon R, Hodkinson A: The Australian National Sub-Acute and Non-Acute Patient Classification (ANSNAP): Report of the National Sub-Acute and Non-Acute Casemix Classification Study. Wollongong, NSW: Centre for Health Service Development, University of Wollongong, 1997.

23. Eagar K, Green J, Gordon R: An Australian casemix classification for palliative care: Technical development and results. Palliat Med 2004;18:217-226.

24. Melching $\mathrm{H}$ : [New legal regulations for palliative care with implications for politics and practice]. Bundesgesundheitsblatt Gesundheitsforschung Gesundheitsschutz 2017;60:4-10.

25. Tong A, Sainsbury P, Craig J: Consolidated criteria for reporting qualitative research (COREQ): A 32-item checklist for interviews and focus groups. Int $\mathrm{J}$ Qual Health Care 2007; 19:349-357.

26. Hodiamont F, Junger S, Leidl R, et al.: Understanding complexity-The palliative care situation as a complex adaptive system. BMC Health Serv Res 2019;19:157.

27. Helfferich C: Die Qualität Qualitativer Daten: Manual Für Die Durchführung Qualitativer Interviews [Quality of Qualitative Data: Manual for Conducting Qualitative Interviews]. Wiesbaden: VS Verlag für Sozialwissenschaften, 2005.

28. Ritchie J, Lewis J, Nicholls CMN, et al.: Qualitative Research Practice: A Guide for Social Science Students and Researchers. London: SAGE Publications, 2013.

29. Pauschalierendes Entgeltsystem für Psychiatrie und Psychosomatik [Lump Sum Reimbursement System for Psychiatry and Psychosomatic Medicine]: https://www.g-drg.de/ PEPP-Entgeltsystem_2018 (last accessed May 6, 2019).

30. Schneider N, Maier BO: Palliativmedizin im gesellschaftlichen System. Gesundheitssystemische und -ökonomische Perspektiven [Palliative care in the social system. Health systemic and health oeconomic perspectives]. In: Schnell MW, Schulz C (eds): Basiswissen Palliativmedizin [Basic Knowledge in Palliative Care]. Heidelberg: Springer Medizin Verlag, 2014, pp. 324-332.

31. Wehkamp K-H, Naegler N: The commercialization of patient-related decision-making in hospitals - a qualitative study of the perceptions of doctors and chief executive officers. Deutsches Ärzteblatt Int 2017;114:797-804.

32. Ryan AM, Rodgers PE: Linking quality and spending to measure value for people with serious illness. J Palliat Med 2018;21:S74-S80.

33. Global Atlas of Palliative Care at the End of Life. Worldwide Palliative Care Alliance, World Health Organization: www.who.int/nmh/Global_Atlas_of_Palliative_Care.pdf (last accessed August 6, 2019).

34. Lagman RL, Walsh D, Davis MP, et al.: All patient refineddiagnostic related group and case mix index in acute care palliative medicine. J Support Oncol 2007;5:145-149. 
35. All Patient Refined Diagnosis Related Groups (APR-DRGs) Version 20.0. Methodology Overview: https://www.hcupus.ahrq.gov/db/nation/nis/APR-DRGsV20Methodology OverviewandBibliography.pdf (last accessed March 21, 2019).

36. Eagar K, Gordon R, Green J, et al.: An Australian casemix classification for palliative care: Lessons and policy implications of a national study. Palliat Med 2004;18:227-233.

37. C-Change: www.kcl.ac.uk/lsm/research/divisions/cicely saunders/research/studies/c-change/c-change.aspx (last accessed April 30, 2019).

38. Developing a New Approach to Palliative Care Funding. Guidance for Using the Adult Palliative Care Currency. Version Number: V1.5: https://www.england.nhs.uk/wpcontent/uploads/2017/03/guidance-using-adult-palliativecare-currency.pdf (last accessed April 30, 2019).
39. Sherry TB: A note on the comparative statics of payfor-performance in health care. Health Econ 2016;25: 637-644.

Address correspondence to:

Eva Schildmann, MSc Department of Palliative Medicine University Hospital Ludwig-Maximilians-Universitaet (LMU) Munich Marchioninistraße 15 81377 München Germany

E-mail: eva.schildmann@med.uni-muenchen.de 